\title{
Seasonal variation in grass water content estimated from proximal sensing and MODIS time series in a Mediterranean Fluxnet site
}

\author{
G. Mendiguren ${ }^{1,2,3,4}$, M. Pilar Martín ${ }^{2,4}$, H. Nieto ${ }^{5}$, J. Pacheco-Labrador ${ }^{2,4}$, and S. Jurdao ${ }^{4,6}$ \\ ${ }^{1}$ Geological Survey of Denmark and Greenland (GEUS), Øster Voldgade 10, 1350 Copenhagen K, Denmark \\ ${ }^{2}$ Instituto de Economía, Geografía y Demografía, Centro de Ciencias Humanas y Sociales, Consejo Superior de \\ Investigaciones Científicas (CSIC), Albasanz 26-28, 28037, Madrid, Spain \\ ${ }^{3}$ Department of Geosciences and Natural Resource Management, University of Copenhagen, Øster Voldgade 10, 1350, \\ Copenhagen K, Denmark \\ ${ }^{4}$ Associated Research Unit GEOLAB 2 \& 6 \\ ${ }^{5}$ Instituto de Agricultura Sostenible, Consejo Superior de Investigaciones Científicas (CSIC), 14080 Córdoba, Spain \\ ${ }^{6}$ Department of Geography and Geology, University of Alcalá, Calle Colegios 2, 28801, Alcalá de Henares, Spain
}

Correspondence to: G. Mendiguren (gmg@geus.dk)

Received: 16 February 2015 - Published in Biogeosciences Discuss.: 13 April 2015

Accepted: 4 September 2015 - Published: 29 September 2015

\begin{abstract}
This study evaluates three different metrics of water content of an herbaceous cover in a Mediterranean wooded grassland (dehesa) ecosystem. Fuel moisture content (FMC), equivalent water thickness (EWT) and canopy water content (CWC) were estimated from proximal sensing and MODIS satellite imagery. Dry matter (Dm) and leaf area index (LAI) connect the three metrics and were also analyzed. Metrics were derived from field sampling of grass cover within a $500 \mathrm{~m}$ MODIS pixel. Hand-held hyperspectral measurements and MODIS images were simultaneously acquired and predictive empirical models were parametrized. Two methods of estimating FMC and CWC using different field protocols were tested in order to evaluate the consistency of the metrics and the relationships with the predictive empirical models. In addition, radiative transfer models (RTM) were used to produce estimates of CWC and FMC, which were compared with the empirical ones.

Results revealed that, for all metrics spatial variability was significantly lower than temporal. Thus we concluded that experimental design should prioritize sampling frequency rather than sample size. Dm variability was high which demonstrates that a constant annual Dm value should not be used to predict EWT from FMC as other previous studies did. Relative root mean square error (RRMSE) evaluated the performance of nine spectral indices to compute each variable. Visible Atmospheri-
\end{abstract}

cally Resistant Index (VARI) provided the lowest explicative power in all cases. For proximal sensing, Global Environment Monitoring Index (GEMI) showed higher statistical relationships both for FMC (RRMSE $=34.5 \%$ ) and EWT $($ RRMSE $=27.43 \%)$ while Normalized Difference Infrared Index (NDII) and Global Vegetation Monitoring Index (GVMI) for CWC (RRMSE $=30.27 \%$ and $31.58 \%$ respectively). When MODIS data were used, results showed an increase in $R^{2}$ and Enhanced Vegetation Index (EVI) as the best predictor for FMC (RRMSE $=33.81 \%$ ) and CWC (RRMSE $=27.56 \%)$ and GEMI for EWT $($ RRMSE $=24.6 \%)$. Differences in the viewing geometry of the platforms can explain these differences as the portion of vegetation observed by MODIS is larger than when using proximal sensing including the spectral response from scattered trees and its shadows. CWC was better predicted than the other two water content metrics, probably because CWC depends on LAI, that shows a notable seasonal variation in this ecosystem. Strong statistical relationship was found between empirical models using indices sensible to chlorophyll activity (NDVI or EVI which are not directly related to water content) due to the close relationship between LAI, water content and chlorophyll activity in grassland cover, which is not true for other types of vegetation such as forest or shrubs. The empirical methods tested outperformed FMC and CWC products based on radiative transfer model inversion. 


\section{Introduction}

Water in leaves is a limiting factor for different physiological processes of vegetation and its deficit causes malfunctioning of different cellular processes. Water is involved in the thermal regulation of plant trough transpiration and also becomes crucial in the uptake of $\mathrm{CO}_{2}$ for photosynthesis (Chaves et al., 2003). It is also fundamental to maintain turgor pressure, which controls different functional processes of plants like cell enlargement or gas exchange (Taiz and Zeiger, 2010).

Different metrics quantify vegetation water content. Fuel Moisture Content (FMC; Desbois et al., 1997), defined as the mass of water per unit mass of vegetation,

$\operatorname{FMC}(\%)=\frac{W_{\text {Fresh }}-W_{\text {Dry }}}{W_{\text {Dry }}} \cdot 100$,

where $W_{\text {Fresh }}$ is the fresh weight of the sample measured in the field and $W_{\text {Dry }}$ is the oven-dried weight. FMC has been extensively used to estimate fire risk and fire propagation (García et al., 2008; Yebra et al., 2008b). Equivalent water thickness (EWT) or leaf water content (LWC), defined as the mass of water per leaf area, measures the thickness of the water layer with the same leaf area (Danson et al., 1992)

$\operatorname{EWT}\left(\mathrm{g} \mathrm{cm}^{-2}\right)=\frac{W_{\text {Fresh }}-W_{\text {Dry }}}{\text { Area }}$,

where Area Leaf is the leaf area.

Several studies showed that EWT can be retrieved from spectral information at leaf level as it is directly related to the water absorption depth of leaves (Ceccato et al., 2001; Datt, 1999). FMC and EWT are related each other since:

$\operatorname{EWT}\left(\mathrm{g} \mathrm{cm}^{-2}\right)=\left(\frac{\mathrm{FMC} \cdot \mathrm{Dm}}{100}\right)$,

where Dm is defined as the ratio of leaf dry weight and leaf area:

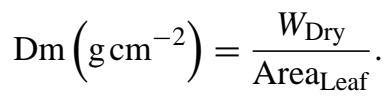

Finally, another metric is the canopy water content (CWC), the mass of water in the canopy per ground area (Cheng et al., 2008; Trombetti et al., 2008). CWC represent the product of EWT and leaf area index (LAI), offering information on vegetation water content at canopy level and can be expressed as:

$\operatorname{CWC}\left(\mathrm{g} \mathrm{cm}^{-2}\right)=\mathrm{EWT} \cdot \mathrm{LAI}$

or

$\operatorname{CWC}\left(\mathrm{g} \mathrm{cm}^{-2}\right)=\frac{W_{\text {Fresh }}-W_{\text {Dry }}}{\text { Area }}$,

where Area denotes for the area of the spatial unit used to collect the sample.
FMC, EWT or CWC are usually estimated from vegetation samples using gravitational methods. Different field and laboratory protocols are used, despite of the need for standardization (Yebra et al., 2013). In several studies FMC is sampled using a bag were 100-200 g of the fresh sample are introduced and considered as representative (Verbesselt et al., 2007; Chuvieco et al., 2003). In other studies vegetation is sampled within a quadrant whose area is used as reference (Sims and Gamon, 2003). However, uncertainties introduced by the different protocols and therefore their comparability are unknown. The three metrics can be used to measure water content, but relationships existing among them remains also unknown. No comparative studies for grasslands have been reported.

Moreover, field sampling is limited and cannot provide estimates at regional or global scales, since it requires interpolation to bridge the gaps in both time and space. Remote sensing is a powerful alternative data source to provide information on vegetation water content as it fills such temporal and spatial gaps. Monitoring vegetation water content with remote sensing benefits agriculture, to control crop production and prevent stress in plants (Peñuelas et al., 1992; SepulcreCantó et al., 2006) and forestry and to assess fire danger associated with vegetation water conditions (Chuvieco et al., 2003, 2004; García et al., 2008; Yebra et al., 2008b).

To estimate plant water content with remote sensing, vegetation spectral reflectance has been primarily related to specific water absorption bands in the short-wave infrared region (SWIR, 1300-2500 nm; Ceccato et al., 2001; Zarco-Tejada et al., 2003). Other studies related vegetation water content to spectral indices that do not include SWIR bands. In the case of grass the relationship with bands in the Visible (VIS) and Near Infrared (NIR) spectral region, has shown a close relationship between vegetation biomass, chlorophyll and water content (Chuvieco et al., 2003, 2004; García et al., 2008; Yebra et al., 2008b) as water stress produces changes in the chlorophyll activity and biomass of the plant. Least squares regression models have served to empirically relate observed measurements of vegetation water content to spectral indices. These models are site-dependent, requiring long data sets for calibration (Chuvieco et al., 2009) and showing different results when the models are extrapolated to other sites using different data sets, making their applicability difficult (Riaño et al., 2005; Yebra et al., 2008a).

Radiative transfer models (RTM) simulate vegetation spectra and are a sound alternative to empirical modeling. They can be applied to different locations to estimate different vegetation parameters, as long as the RTM is a true representation of the vegetation canopy. For example, Trombetti et al. (2008) predicted CWC for the continental US using RTM PROSAILH (Jacquemoud et al., 1995) simulations. Their model was calibrated with CWC from Airborne Visible/Infrared Imaging Spectrometer (AVIRIS) hyperspectral water absorption bands. Yebra et al. (2008b) used also PROSAILH to quantify FMC, and more recently, Jurdao et 
al. (2013) inverted the RTM GEOSAIL (Huemmrich, 2001) combined with PROSAILH to estimate FMC. The estimations were validated with extensive field sampling data in Spain. RTM estimates are based on a physical principle, and one of the advantages is that they are not constrained to local conditions as is the case of empirically derived relationships. Therefore, in theory they can be extensively applied at different locations with good results (Yebra et al., 2008a, b). This study compares the performance of the different empirically derived models and RTM-based estimates models. The former were created establishing empirical relationships between three different metrics of vegetation water content measured simultaneously in the field (FMC, EWT, CWC) and nine spectral indices calculated at two scales, from proximal sensing and MODIS spectral data. In addition Dm and LAI were also analyzed in order to connect metrics which estimates water content at leaf and canopy level. Firstly, an analysis of the temporal and spatial variability of the different vegetation samples collected in the field was conducted to evaluate which biophysical parameter offers more information. Secondly, the performance statistics of the fitting equations were evaluated to select the most accurate empirical models. Finally, these models were compared to three RTM based estimates, proposed in the literature to derive two FMC (Jurdao et al., 2013; Yebra et al., 2008b) and the other for CWC (Trombetti et al., 2008).

\section{Methods}

\subsection{Site description}

The study site is located at Las Majadas del Tiétar (Spain) FLUXNET site (http://fluxnet.ornl.gov/site/440; Fig. 1). The area is a dehesa, a typical Mediterranean wooded grassland, ecosystem that occupies about $4 \%$ (2.5 Mha) of the Iberian Peninsula (Castro, 1997). Common tree species are different varieties of oaks, here mostly Quercus ilex subsp. ballota (L.), whose acorns and leaves are mainly used as forage for pigs and cows, respectively. The scattered oak trees have a $9 \mathrm{~m}$ mean height and $6 \mathrm{~m}$ mean crown diameter. Due to its deep and wide root system, this species is resistant to long drought periods (Camarero et al., 2012). Short grassland covers $86 \%$ of the area that is managed for cow shepherding. It is mainly composed by Rumex acetosella, L., Plantago carinata Schrad, Trifolium subterraneum L., Cynodon dactylon (L.) Pers., Taraxacum dens -leonis Desf. and Vulpia myuros (L.) C. C. Gmel. During the summer, grass dries out rapidly and turns into dead matter. Summers are hot and dry, with $30^{\circ} \mathrm{C}$ daily average temperature and only $67 \mathrm{~mm}$ total precipitation, which are not representative of mean annual $16.7^{\circ} \mathrm{C}$ and $572 \mathrm{~mm}$. The average altitude is $256 \mathrm{~m}$ above mean sea level. Soils are lixisols with an average thickness of $80 \mathrm{~cm}$. Due to the presence of a clay layer in some of the areas, small water pools may appear

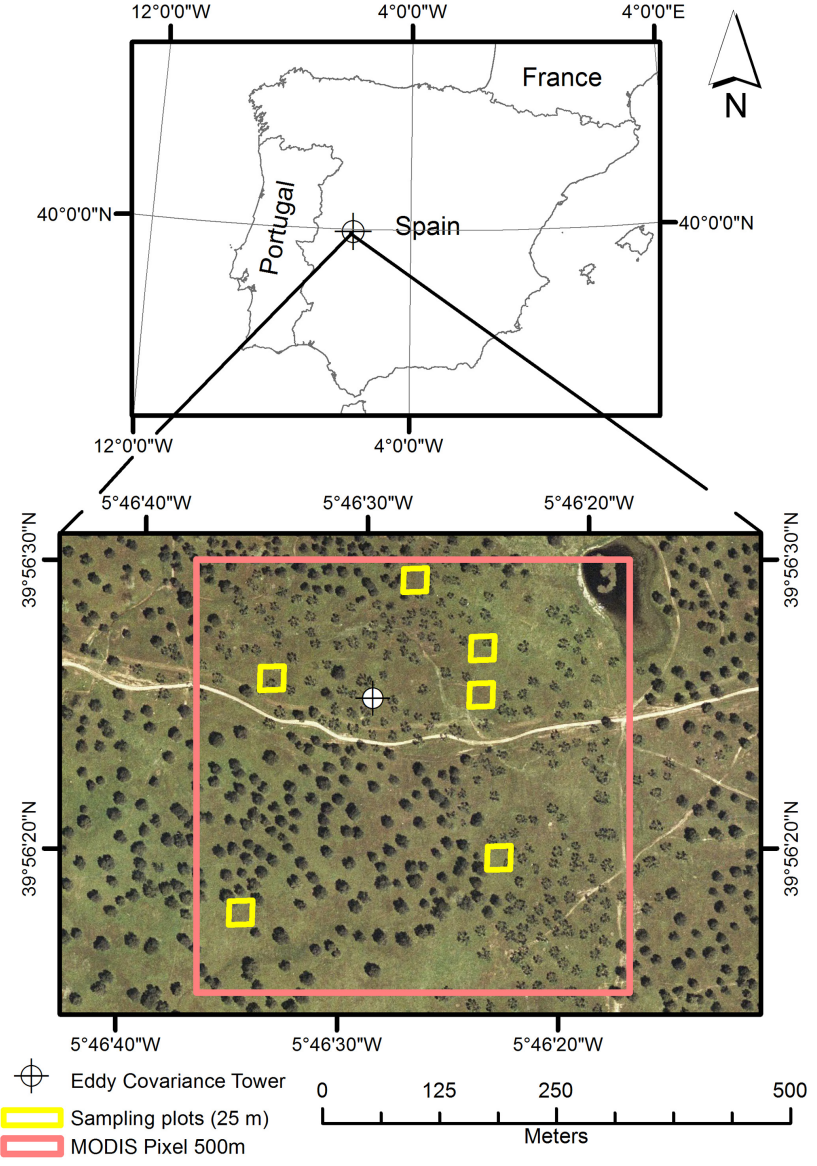

Figure 1. Plots sampled near the FLUXNET tower within the $500 \mathrm{~m}$ MODIS pixel at Las Majadas del Tiétar (Spain) study site.

in winter after rainy periods. The occurrence of this type of ecosystem in Mediterranean areas worldwide, the need to track the responses to water stress conditions, together with the presence of a FLUXNET eddy covariance flux tower (http://fluxnet.ornl.gov/site/440) justifies the selection of this site.

\subsection{Field data}

\subsubsection{Vegetation sampling}

Grass water status was estimated through destructively sampling every 2 weeks from April 2009 to April 2011. Sampling was performed assuring no rain occurred in the two previous days to avoid sampling superficial water on the leaves. During the 2009 summer, when grass became completely dry, samples were not collected. However, to ensure the time series continuity of at least one phenological cycle, sampling was restated throughout the summer of 2010. This sampling strategy led to a total of 21 valid sampling days for the whole study period. 


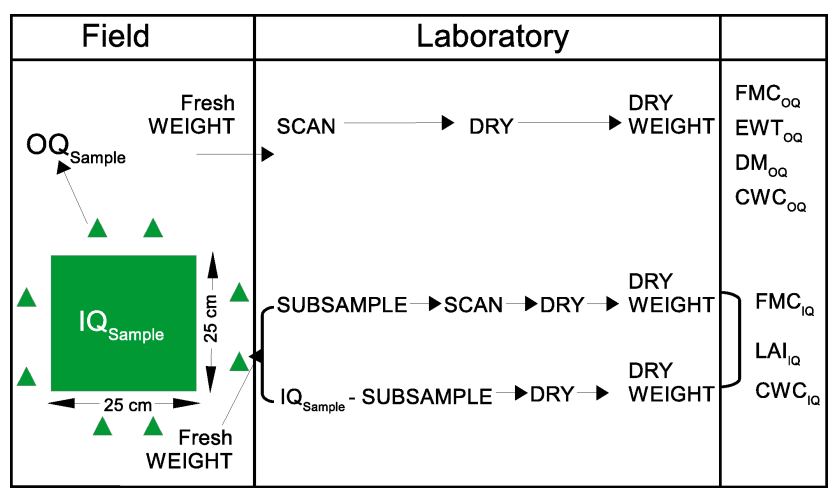

Figure 2. Scheme showing the different samples collected in the field and how they are processed in the laboratory. Metrics obtained as results are also indicated in the last column.

Six $25 \times 25 \mathrm{~m}$ plots were randomly located within the $500 \mathrm{~m}$ MODIS pixel that contained the eddy covariance flux tower that was established as the center of the study site (Fig. 1). Three grass samples were collected from $25 \times 25$ $\mathrm{cm}$ quadrants randomly positioned within each plot. All rooted grasses were collected inside the quadrant using clippers (IQSample hereafter). Additionally, a different sampling strategy was tested and a smaller sample was collected outside of the quadrant but nearby, containing a representative proportion of surrounding species ( $O Q_{\text {Sample }}$ hereafter) (Fig. 2). All samples were placed in sealed plastic bags, weighed on a scale with $0.01 \mathrm{~g}$ precision and then transported in a cooler to the laboratory. Every $\mathrm{OQ}_{\text {Sample }}$ and a sub-sample from each IQsample were scanned at 150 pixels per inch (ppi) in an Epson Perfection V30 color scanner (Epson American Inc., Long Beach, CA, USA). Leaf area was calculated automatically from the scanned images using the unsupervised classification algorithm ISOCLUS with 16 iterations in PCI Geomatica (PCI Geomatics, Richmond Hill, Ontario, Canada). All samples were then placed in an oven for $48 \mathrm{~h}$ at a constant temperature of $60^{\circ} \mathrm{C}$ to obtain their dry weight. Five biophysical variables were obtained from the collected vegetation samples: FMC, EWT, Dm, CWC and LAI.

FMC was determined from the fresh and dry weights of both the $\mathrm{IQ}_{\text {Sample }}\left(\mathrm{FMC}_{\mathrm{IQ}}\right)$ and the $\mathrm{OQ}_{\text {Sample }}\left(\mathrm{FMC}_{\mathrm{OQ}}\right)$ according to Eq. (1). The $\mathrm{OQ}_{\text {sample }}$ permitted to calculate both, EWT and Dm using Eqs. (2) and Eq. (4) respectively, since fresh/dry weight and leaf area were measured. The IQsample was not used in this case as it was unfeasible to obtain the area of the total sample collected inside the quadrant and neither was the fresh weight of a sub-sample.

CWC was calculated from two different approaches. In the first one, information corresponding to the $\mathrm{IQ}_{\text {sample }}$ and $\mathrm{OQ}_{\text {sample }}$ were combined using Eq. (5).

The grass height was very short due to cow shepherding during some periods, so the only feasible technique to estimate LAI was using gravitational methods (He et al., 2007).
The biomass to leaf area ratio of a sub-sample inside the IQSample to the total quadrant's biomass provided LAI using the following expression (Eq. 7):

$\operatorname{LAI}\left(\mathrm{cm}^{2} \mathrm{~cm}^{-2}\right)=\frac{\frac{W_{\text {Dry }}}{W_{\text {Dry }}^{\text {Sub }}} \text {Area }_{\text {Leaf }}^{\text {Sub }}}{\text { Area }}$,

where $W_{\text {Dry }}$ is the total dry weight of the whole sample inside the IQ $\mathrm{I}_{\text {Sample }}, W_{\text {Dry }}^{\text {Sub }}$ is the dry weight of a sub-sample of $W_{\text {Dry }}$, $\mathrm{Area}_{\text {Leaf }}^{\mathrm{Sub}}$ is the sub-sample leaf area and Area is the total area of the quadrant. The second approach measured CWC from the fresh and dry weight difference of the IQSample as in (Eq. 6).

\subsubsection{Proximal sensing}

Simultaneously to vegetation sampling, proximal sensing data were acquired using an ASD FieldSpec ${ }^{\circledR} 3$ spectroradiometer (http://www.asdi.com/) along NE-SW and NW-SE transects in each $25 \times 25 \mathrm{~m}$ plot. This instrument measures Hemispherical-Conical Reflectance Factor (HCRF) from 350 to $2500 \mathrm{~nm}$. Before measuring along each transect, dark current was recorded, instrument settings were optimized and reference spectra were acquired using a Spectralon ${ }^{\circledR} 99 \%$ reflective reference panel (Labsphere Inc., North Sutton, NH, USA). All measurements were taken under clear sky within about $\pm 2 \mathrm{~h}$ from local solar noon, to guarantee homogeneous illumination and maximum solar irradiance. Sky conditions were recorded in the field logs, and a quality control check removed the spectra where illumination changes may have occurred after calibration. The ASD was handled using bare fiber. Spectra were acquired at approximately $1.2 \mathrm{~m}$ height, rendering a sensor footprint diameter of about $53 \mathrm{~cm}$, since nominal FOV is $25^{\circ}$.

An average of approximately 10 spectral measurements was calculated for each transect and this information was spectrally resampled to MODIS bands using ITT ENVI 4.7. (EXELIS, Boulder CO, USA).

\subsubsection{MODIS data images}

MODIS Terra daily surface reflectance (MOD09GA) data from 1 April 2009 to 15 April 2011 were downloaded from NASA Land Processes Distributed Active Archive Center (LP DAAC) at the USGS/Earth Resources Observation and Science (EROS) Center, Sioux Falls, South Dakota, USA. This product includes the reflectance of bands 1 to 7, from 469 to $2130 \mathrm{~nm}$ at $500 \mathrm{~m}$ spatial resolution, as well as sensor and solar observation angles and quality flags at $1 \mathrm{~km}$. A script programmed in Matlab (Mathworks, Batick, Massachusetts, USA) extracted the MODIS pixel value of our study site from all the images to build the time series. The impact of angular effects on reflectance was reduced by removing images with sensor zenith angles wider than $20^{\circ}$, which also assures the accuracy of the geometrical location of the 
Table 1. Spectral indices calculated using field HCRF measurements and MODIS data. $B_{x}$ designates the band number corresponding to the MOD09GA product surface reflectance product.

\begin{tabular}{|c|c|c|}
\hline Index & Formula & Reference \\
\hline $\begin{array}{l}\text { Normalized difference vegetation } \\
\text { index (NDVI) }\end{array}$ & $\mathrm{NDVI}=\frac{B_{2}-B_{1}}{B_{2}+B_{1}}$ & Rouse et al. (1973) \\
\hline $\begin{array}{l}\text { Enhanced Vegetation } \\
\text { Index (EVI) }\end{array}$ & $\mathrm{EVI}=2.5 \cdot\left(\frac{B_{2}-B_{1}}{B_{2}+6 \cdot B_{1}-7.5 \cdot B_{3}}\right)$ & Huete et al. (2002) \\
\hline $\begin{array}{l}\text { Normalized Difference } \\
\text { Water Index (NDWI) }\end{array}$ & $\mathrm{NDWI}=\frac{B_{2}-B_{5}}{B_{2}+B_{5}}$ & Gao (1996) \\
\hline $\begin{array}{l}\text { Normalized Difference } \\
\text { Infrared Index (NDII) }\end{array}$ & $\mathrm{NDII}=\frac{B_{2}-B_{6}}{B_{2}+B_{6}}$ & Hardisky et al. (1983) \\
\hline $\begin{array}{l}\text { Simple Ratio Water } \\
\text { Index (SRWI) }\end{array}$ & $\mathrm{SRWI}=\frac{B_{2}}{B_{5}}$ & Zarco-Tejada et al. (2003) \\
\hline $\begin{array}{l}\text { Soil Adjusted Vegetation } \\
\text { Index (SAVI) }\end{array}$ & $\begin{array}{l}\mathrm{SAVI}=\left(\frac{B_{2}-B_{1}}{B_{2}+B_{1}+L}\right) \cdot(1+L) \\
\text { where } L=0.5\end{array}$ & Huete (1988) \\
\hline $\begin{array}{l}\text { Global Environment Monitoring } \\
\text { Index (GEMI) }\end{array}$ & $\begin{array}{l}\text { GEMI }=\eta \cdot(1-0.25 \eta)-\frac{B_{1}-0.125}{1-B_{1}} \\
\text { where } \eta=\frac{2 \cdot\left(B_{2}^{2}-B_{1}^{2}\right)+1.5 \cdot B_{2}+0.5 \cdot B_{2}}{B_{2}+B_{1}+0.5}\end{array}$ & Pinty and Verstraete (1992) \\
\hline $\begin{array}{l}\text { Visible Atmospherically } \\
\text { Resistant Index (VARI) }\end{array}$ & $\mathrm{VARI}=\frac{B_{4}-B_{1}}{B_{4}+B_{1}-B_{3}}$ & Gitelson et al. (2002a) \\
\hline $\begin{array}{l}\text { Global Vegetation Monitoring } \\
\text { Index (GVMI) }\end{array}$ & $\mathrm{GVMI}=\frac{\left(\mathrm{NIR}_{\mathrm{REC}}^{*}+0.1\right)-(\mathrm{SWIR}-0.02)}{\left(\mathrm{NIR}_{\mathrm{REC}}^{*}+0.1\right)+(\mathrm{SWIR}-0.02)}$ & Ceccato et al. (2002) \\
\hline Central band wavelength & $\begin{array}{l}\mathrm{B} 1=645.5 \mathrm{~nm}, \mathrm{~B} 2=856.5 \mathrm{~nm}, \mathrm{~B} 3=465.6 \mathrm{~nm}, \\
\mathrm{~B} 4=553.6 \mathrm{~nm}, \mathrm{~B} 5=1241.6 \mathrm{~nm}, \mathrm{~B} 6=1629.1 \mathrm{~nm}, \mathrm{~B} 7=2114.1 \mathrm{~nm}\end{array}$ & \\
\hline
\end{tabular}

NIR $_{\text {REC }}$ stands for the information in the Near Infra Red rectified as the index was designed for SPOT-VEGETATION (Ceccato et al., 2002). In this study the index was calculated using the spectral bands from MODIS corresponding to that B2 for the NIR and B5 for the SWIR regions.

pixel (Wolfe et al., 2002). In addition, the quality flag layer eliminated images under clouds, cloud shadows and/or with high atmospheric aerosol content. The algorithm selected the closest valid MODIS image to the field sampling day within \pm 5 days window, or the MODIS image acquired before the sampling day in case they were equal. Minimal time lag between sensor and field data reduces the chances of discrepancy, as grassland grazing could affect LAI in a short period of time. This led to a total of 14 days of MODIS data with coincident proximal sensing measurements and field data.

\subsection{Vegetation indices}

For the study nine spectral indices were calculated from proximal and MODIS reflectance data according to the equations in Table 1. The indices selected to estimate the biophysical variables included bands in the water absorption SWIR region (Faurtyot and Baret, 1997) and bands sensitive to vegetation greenness and structure in the NIR region (Paltridge and Barber, 1988; Yebra et al., 2008b).

\subsection{RTM-based water metrics estimates}

In order to compare performance with the empirical derived models, three RTM-based models were used to estimate CWC (Trombetti et al., 2008) and FMC (Yebra et al., 2008b; Jurdao et al., 2013). As for the empirical models, the spectral information used to run the RTMs was the one obtained using proximal sensing and MODIS data.

\subsubsection{CWC}

CWC was estimated in the study site following Trombetti et al. (2008). This method uses PROSAILH RTM (Jacquemoud and Baret, 1990; Jacquemoud et al., 1995) and Artificial Neural Networks (ANN) to estimate CWC. Trombetti et al. (2008) trained their model by using MODIS synthetic spectra based on a set of empirical relationships. Different MODIS spectra combinations and vegetation indices were later used as input variables to train a neural network and obtaining as outputs CWC, leaf water content, and LAI. The 


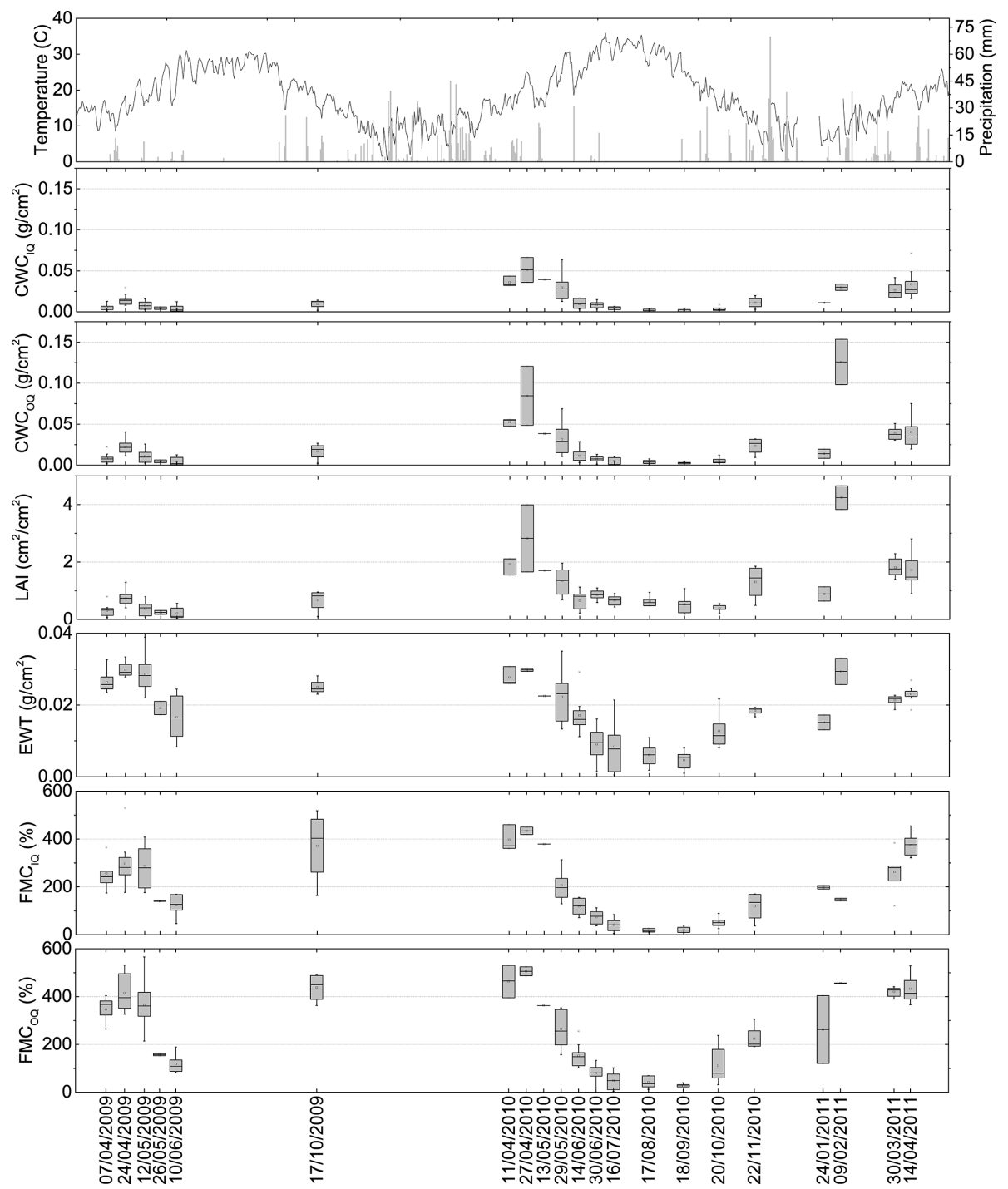

Figure 3. Box plot showing the temporal evolution of field biophysical variables measured. Filled points represent the median of the daily measurements, the boxes indicate the position of the 1st and 3rd quartile, lines delimit the maximum and minimum values. Line inside the boxes showed the median value of the day and the point the mean value. Precipitation is represented using bars and temperature is represented with a solid line.

outputs were validated against AVIRIS CWC and MODIS MOD15A2 LAI product. Multiple linear regression approach is later used to establish the equations for each landcover type. In our case we used the original calibration from Trombetti et al. (2008) for grassland.

Further details on this method can be found in Trombetti et al. (2008).

\subsubsection{FMC}

The FMC estimates are based on the look-up table (LUT) inversion technique. This technique compares each observed spectra against previously generated spectra stored in a LUT. In this study two LUTs were tested. One specifically designated for grassland based on the study of Yebra et al. (2008b) and that was generated using PROSAILH (Jacquemoud and Baret, 1990). The second LUT was generated using a link between PROSAILH (Jacquemoud and Baret, 1990; Jacquemoud et al., 1995) at leaf level and GEOSAIL RTM (Huemmrich, 2001) at canopy level and originally proposed to estimate FMC in a mixed-oak-tree-grassland cover (Jurdao et al., 2013). This model includes some additional parameters that allow to account for shadows, especially important in areas with disperse tree coverage as is the case in our study site.

Further details on these methods can be found in Yebra et al. (2008b) and Jurdao et al. (2013). 


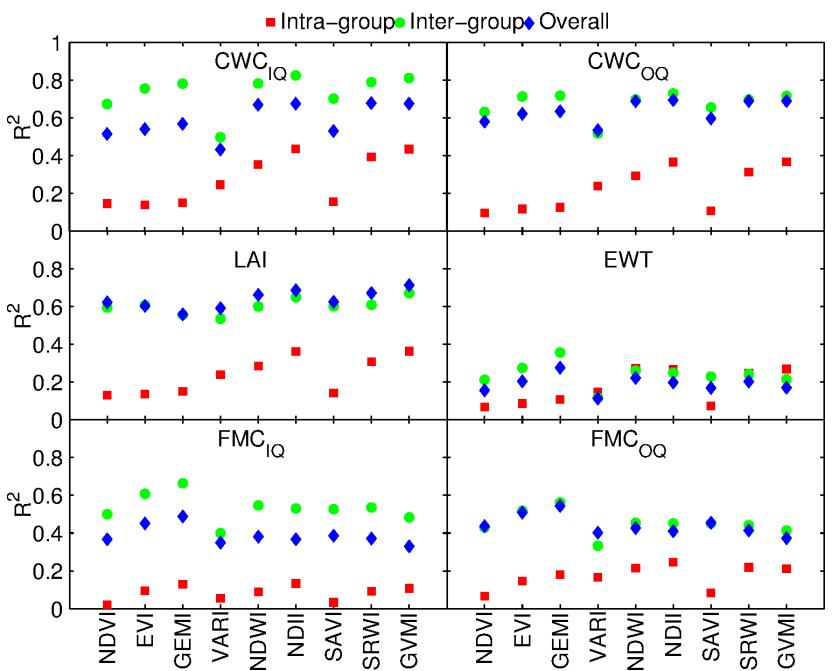

Figure 4. Intra-group, inter-group and overall $R^{2}$ values between proximal sensing spectral indexes and biophysical variables measured in the field.

\subsection{Empirical models fitting}

Intra-group, inter-group and overall $R^{2}$ values between $\mathrm{FMC}_{\mathrm{IQ}}, \mathrm{FMC}_{\mathrm{OQ}}$, EWT, $\mathrm{CWC}_{\mathrm{IQ}}, \mathrm{CWC}_{\mathrm{OQ}}$ or $\mathrm{LAI}$, and each of the proximal sensing spectral indices were calculated to investigate their variability within the $500 \mathrm{~m}$ MODIS pixel. More specifically, the intra-group $R^{2}$ offers information about the spatial variability, due to the collection of samples from different plots within the MODIS pixel. A linear regression model was created for each sampling day where the biophysical variable and the spectral index were the dependent and the independent variable, respectively. The average $R^{2}$ of all the regression models for each day provided the intragroup $R^{2}$. Instead, the inter-group $R^{2}$ explains the temporal variability due to the collection of the samples on different days. In this case, the biophysical variable and the spectral index for all plots were averaged for each sampling day. The linear regression model of these averaged values determined the inter-group $R^{2}$. To explain temporal and spatial variability together, the overall $R^{2}$ fitted in a single regression model including all plots and sampling days for each spectral index and biophysical variable.

Later, using the mean values of each biophysical variable and the proximal sensing spectral indices, a univariate linear regression model was applied. The same procedure was repeated for MODIS data. Bootstrapping techniques evaluated the empirical model robustness, which is a valid alternative to traditional leave-one-out methods to validate regression models predictability according to Richter et al. (2012) and following Steyerberg et al. (2001) that recommends two hundred simulations. Later the median value of each statistics was used as indicative of its performance. Root Mean Square Error (RMSE), Relative Root Mean Square Error (RRMSE),

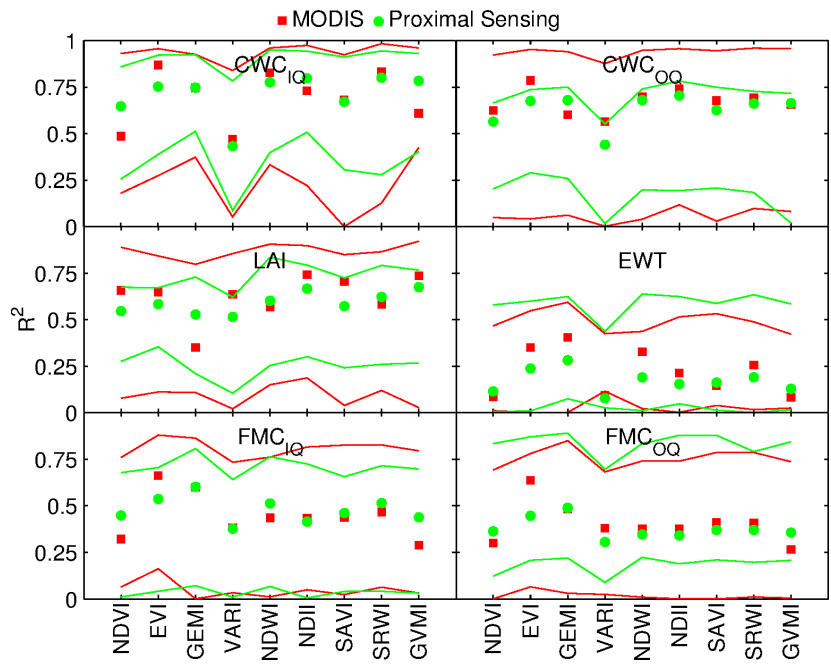

Figure 5. Determination coefficient for proximal (green circles) and MODIS (red squares) empirical models after bootstrap. Upper and lower limits of the confidence intervals for MODIS and proximal sensing are presented.

determination coefficient $\left(R^{2}\right)$ and Taylor's diagrams evaluated the models' performance. The RMSE measured the error in the estimation of the biophysical variable by each model:

$\mathrm{RMSE}=\sqrt{\frac{1}{n} \sum_{i=1}^{n}\left(V_{\mathrm{est}}^{i}-V_{\mathrm{obs}}^{i}\right)}$,

where $V_{\mathrm{est}}^{i}$ is the estimated variable and $V_{\mathrm{obs}}^{i}, V_{\mathrm{obs}}^{i}$ is its observed field measurement. RMSE cannot compare the error of different variables with different units. To address this limitation in order to compare the model performances between different variables, RRMSE divides RMSE by the average of the observed values ( $\bar{V}_{\text {obs }}$; Richter et al., 2012):

RRMSE $=100 \frac{\text { RMSE }}{\bar{V}_{\text {obs }}}$.

The $R^{2}$ measures the proportion of variance explained by the model and is calculated as:

$R^{2}=1-\frac{\sigma_{\mathrm{r}}^{2}}{\sigma^{2}}$,

where $\sigma_{\mathrm{r}}^{2}$ represents the residual variance and $\sigma^{2}$ is the variance of the dependent variable.

\subsection{Comparing performance between empirical and RTM-based estimates}

Taylor diagrams (Taylor, 2001) allowed the comparison between the FMC and CWC predicted by empirical models fit and the RTM inversion estimates. In these plots the observed variable and its standard deviation (SD) are plotted in the 
$x$ axes. RMSE is represented as semicircles centered at the observed data. The correlation coefficient $(r)$ is displayed in the azimuthal position. Best models are closer in the plot to the observed measurement; therefore they will have a high $r$, a low RMSE and an SD similar to the observed values.

\section{Results}

\subsection{Empirical models fitting}

All variables showed similar temporal evolution, a strong variability controlled by the meteorological conditions with a peak in spring and second minor peak in the winter except Dm (Fig. 3). Dm fluctuated throughout the year and exhibited its highest values in the summer. The $47 \%$ Coefficient of Variation (CV) for Dm was less than for $\mathrm{CWC}_{\mathrm{IQ}}(\mathrm{CV}=95 \%), \mathrm{CWC}_{\mathrm{OQ}}(\mathrm{CV}=0.95 \%), \mathrm{FMC}_{\mathrm{IQ}}$ $(\mathrm{CV}=60 \%)$ and $\mathrm{FMC}_{\mathrm{OQ}}(\mathrm{CV}=56 \%)$, but higher than for EWT $(\mathrm{CV}=38 \%)$. A higher precipitation in the spring of 2010 compared to previous years translated into higher FMC, $\mathrm{CWC}$ and $\mathrm{LAI}$ values. $\mathrm{FMC}_{\mathrm{OQ}}$ and $\mathrm{CWC}_{\mathrm{OQ}}$, calculated from the $\mathrm{OQ}_{\text {sample, }}$, presented similar trends but in some cases higher values than $\mathrm{FMC}_{\mathrm{IQ}}$ and $\mathrm{CWC}_{\mathrm{IQ}}$, calculated from the IQSample.

A low intra-group $R^{2}$ for all the variables indicates a low spatial variability between plots (Fig. 4). Contrary, the high inter-group $R^{2}$ also for all variables points to the high temporal variability between sampling dates. The main differences between variables occurred for overall $R^{2}$. Similar overall and inter-group $R^{2}$ values for $\mathrm{CWC}_{\mathrm{OQ}}$ and $\mathrm{FMC}_{\mathrm{OQ}}$ indicated that the combination of the temporal and spatial factors matched in importance each factor on its own. Instead, overall $R^{2}$ for $\mathrm{CWC}_{\mathrm{IQ}}$ and $\mathrm{FMC}_{\mathrm{IQ}}$ laid in between the intergroup and the intra-group $R^{2}$ underling the temporal factor as the main source of variation. GEMI offers the best $R^{2}$ for all variables while VARI had the weakest $R^{2}$.

The explicative model with the highest $R^{2}$ to retrieve each variable differed between proximal sensing and MODIS (Fig. 5). $\mathrm{FMC}_{\mathrm{OQ}}$ and $\mathrm{FMC}_{\mathrm{IQ}}$ showed the best correlations with GEMI from proximal sensing data but EVI was the index that presented the highest $R^{2}$ when using MODIS images. EWT offered the poorest adjustments among all variables analyzed both for proximal sensing and MODIS data. In this case GEMI was the best predictor. NDII and GVMI were the most accurate predictors for LAI, $\mathrm{CWC}_{\mathrm{OQ}}$ and $\mathrm{CWC}_{\mathrm{IQ}}$ with proximal sensing. When using MODIS, the most accurate results for LAI were achieved with NDII and GVMI, but EVI did so for $\mathrm{CWC}_{\mathrm{OQ}}$ and $\mathrm{CWC}_{\mathrm{IQ}}$. When the $\mathrm{IQ}_{\text {sample }}$ was used instead of the OQ $\mathrm{Q}_{\text {sample }}$, both FMC and CWC showed higher $R^{2}$ results (Fig. 5) with lower RRMSE, although the RRMSE results obtained presented small differences (Fig. 6).

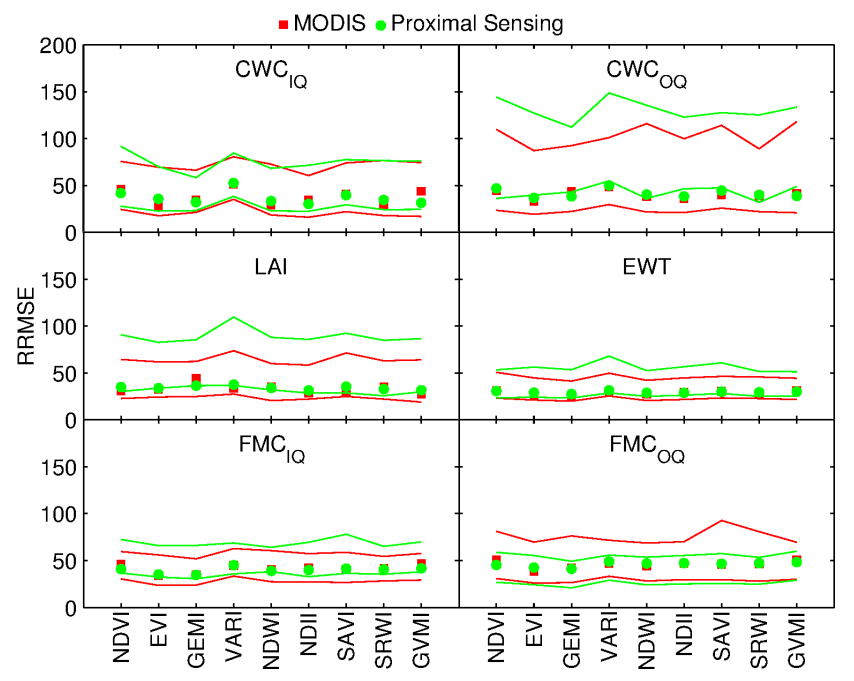

Figure 6. Relative root mean square error for proximal (green circles) and MODIS (red squares) empirical models after bootstrap. Upper and lower limits of the confidence intervals for MODIS and Proximal sensing are presented.

Smaller confidence intervals of $R^{2}$ were observed when proximal sensing reflectance was used with the exception of EWT in which MODIS presented smaller intervals.

\subsection{Comparing performance between empirical-based and RTM estimates}

Taylor diagrams in Figs. 7 and 8 compare FMC and CWC estimates using spectral indices and RTM. In the case of $\mathrm{FMC}_{\mathrm{IQ}}$ from proximal sensing (Fig. 7 left), RTMs are distant from empirical index-based models. They presented higher RMSE and lower $r$ than the spectral indices whereas RTM $\mathrm{SD}$ was more similar to the observed values. In the case of $\mathrm{FMC}_{\mathrm{IQ}}$ estimated from MODIS (Fig. 7 right), RTMs were closer to the empirical models in the Taylor diagram and therefore perform more similar to those. For $\mathrm{CWC}_{\mathrm{IQ}}$ (Fig. 8), the differences between the empirical and RTMs are larger. Using proximal sensing data (Fig. 8 left), RTM overestimated the SD of the observed $\mathrm{CWC}_{\mathrm{IQ}}$. Using MODIS (Fig. 8 right), RTM showed a very high overestimation of the $\mathrm{CWC}_{\mathrm{IQ}}$.

Temporal evolution of the biophysical variables estimated using the most explicative model for proximal sensing and MODIS in Figs. 5 and 6 are shown in Fig. 9. Fitting equations for the different variables are shown in Table 2. Both sensors predicted well EWT, $\mathrm{FMC}_{\mathrm{IQ}}$ and $\mathrm{FMC}_{\mathrm{OQ}}$ but showed an overestimation, especially during the dry season. On the contrary, the models for $\mathrm{LAI}, \mathrm{CWC}_{\mathrm{OQ}}$ and $\mathrm{CWC}_{\mathrm{IQ}}$ adjusted well even during the dry season. 
Table 2. Empirical fitting equations obtained after bootstrap.

\begin{tabular}{|c|c|}
\hline $\begin{array}{l}\text { Fitting equation } \\
\text { Proximal Sensing }\end{array}$ & $\begin{array}{l}\text { Fitting equation } \\
\text { MODIS }\end{array}$ \\
\hline $\mathrm{FMC}_{\mathrm{OQ}}=(1184.400 \times \mathrm{GEMI})-734.405$ & $\mathrm{FMC}_{\mathrm{OQ}}=(1727.326 \times \mathrm{EVI})-216.433$ \\
\hline $\mathrm{FMC}_{\mathrm{IQ}}=(999.707 \times \mathrm{GEMI})-626.932$ & $\mathrm{FMC}_{\mathrm{IQ}}=(1398.385 \times \mathrm{EVI})-173.518$ \\
\hline $\mathrm{EWT}=(0.029 \times \mathrm{EVI})+0.011$ & $\mathrm{EWT}=(0.059 \times \mathrm{EVI})+0.003$ \\
\hline $\mathrm{LAI}=(2.621 \times \mathrm{NDII})+1.268$ & $\mathrm{LAI}=(3.524 \times \mathrm{NDII})+1.189$ \\
\hline $\mathrm{CWC}_{\mathrm{OQ}}=(0.075 \times \mathrm{NDII})+0.029$ & $\mathrm{CWC}_{\mathrm{OQ}}=(0.195 \times \mathrm{EVI})-0.032$ \\
\hline $\mathrm{CWC}_{\mathrm{IQ}}=(0.063 \times \mathrm{NDII})+0.023$ & $\mathrm{CWC}_{\mathrm{IQ}}=(0.157 \times \mathrm{EVI})-0.026$ \\
\hline
\end{tabular}
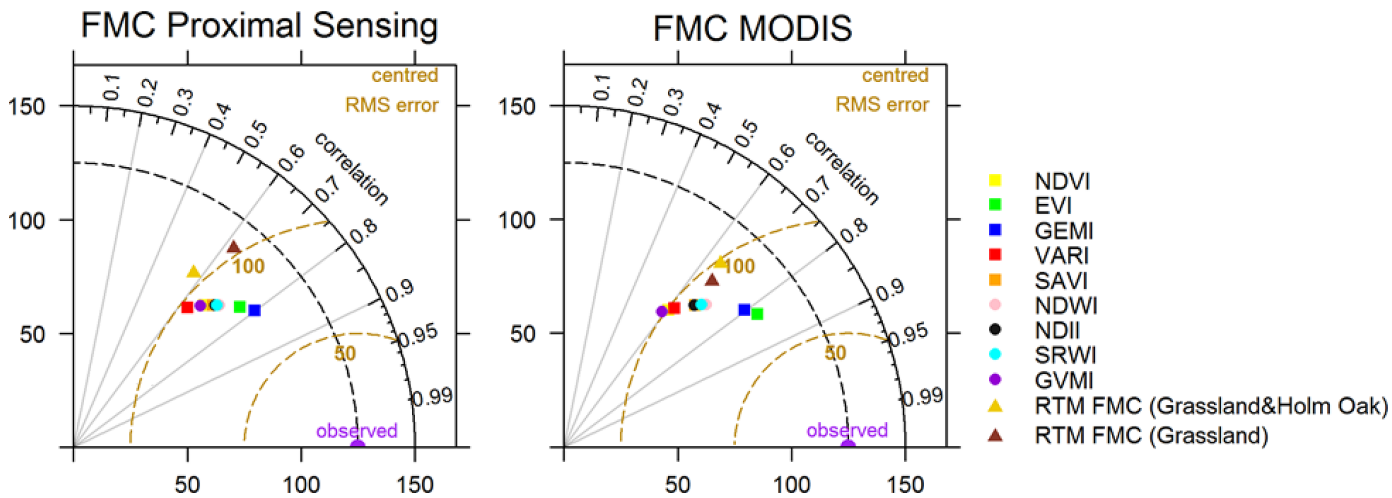

Figure 7. Comparison of empirical vs RTM models to estimate FMC with proximal sensing (left) and MODIS (right). RTM FMC (Grassland) obtained from the LUT proposed by (Yebra et al., 2008b). RTM FMC (Grassland \& Holm Oak) obtained from the LUT proposed by Jurdao et al. (2013).

\section{Discussion}

Results revealed that Dm varies significantly throughout the year $(\mathrm{CV}=47 \%)$ with high values in the summer. These changes could be related to the temporal variation in plant community structure, species composition and diversity in this ecosystem (Casado et al., 1986). Summer should be the best time of the year to invert RTM and predict Dm, since leaves are drier and therefore EWT does mask the Dm spectral absorption signal (Riaño et al., 2005). Casas et al. (2014) applied a constant annual Dm value from the literature to successfully predict seasonal variations in EWT and CWC. However, our study suggests that, due to the high seasonal variation in Dm, a constant annual value would not be recommended in grassland ecosystems as the one analyzed in this work.

The high inter-group and low intra-group $R^{2}$ implies that the temporal trend is much more critical than the spatial variation within the MODIS pixel (Fig. 4). Therefore, the strategy to better capture the variability of grass water content in this ecosystem should consist in increasing the number of samples in time but sampling a lower number of plots per day. In addition, $\mathrm{CWC}_{\mathrm{IQ}}$ and $\mathrm{FMC}_{\mathrm{IQ}}$, generated from larger sample sizes than $\mathrm{CWC}_{\mathrm{OQ}}$ and $\mathrm{FMC}_{\mathrm{OQ}}$, presented higher inter-group $R^{2}$ values, which indicate a better characterization of the temporal variability. Even though similar conclu- sion were obtained using the two strategies the results in this study showed that the higher $R^{2}$ are found in the case of the $\mathrm{IQ}_{\text {Sample }}$. Using the quadrant also presented some advantages as it allows not just the retrieval of FMC but also CWC (as in Eq. 6) without going through the time-consuming leaf scanning process to retrieve leaf area needed to estimate EWT. This suggests the need to standardize sampling protocols for the estimation of vegetation biophysical parameters to ensure data quality, repeatability and to facilitate accurate cross comparison from different studies. Some initiatives already exist to facilitate this standardization, as the Global Terrestrial Carbon System (GTOS) guidelines in support of carbon cycle science (Law et al., 2008). However, currently there is no international backbone that ensures this and an agreement in the protocols is needed in order to validate remote-sensing products.

CWC was better predicted than the other two water content metrics, FMC and EWT (Fig. 4). CWC depends on LAI which is showing higher correlation values to the empirical models than other metrics such as FMC or EWT. Some studies have shown that LAI contributions to total reflectance variability is much higher than water (Bowyer and Danson, 2004) for this reason also, CWC should provide more accurate retrievals than FMC or EWT. It is possible to have the same FMC and EWT for different LAI and hence different CWC and amount of soil background, which will change its 
CWC Proximal Sensing

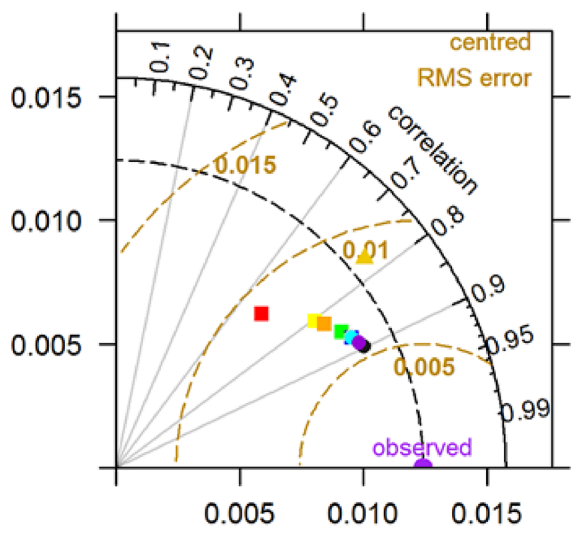

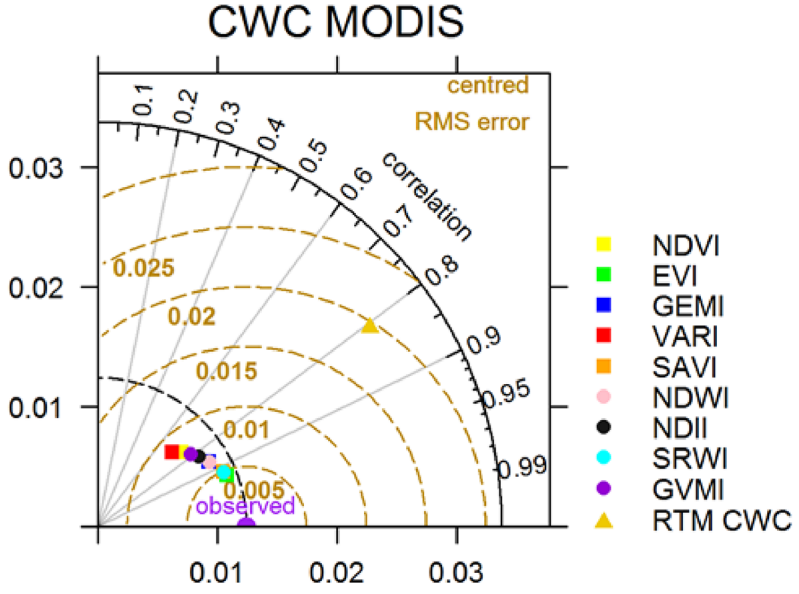

Figure 8. Comparison of empirical vs RTM models to estimate CWC with proximal sensing (left) and MODIS (right). RTM CWC is based on Trombetti et al. (2008).

reflectance. Yebra et al. (2013) demonstrated through PROSAILH simulations how a very different CWC for the same EWT based on changes of LAI translates into a large range of NDII values. Our results confirm this theoretical assumption described in Yebra et al. (2013). This issue is especially critical over areas like the one analyzed in this work with an herbaceous cover exhibiting large dynamic annual growth. Very low $R^{2}$ values were obtained in this study regarding the EWT. More research needs to be done in this line as EWT is a key input parameter in many RTM.

The empirical methods estimated FMC and CWC with slightly different results for proximal sensing and MODIS (Figs. 5 and 6). While GEMI and NDII were the most accurate for FMC and CWC respectively from proximal sensing in our study; EVI was the most explicative estimator of both variables from MODIS. The relationship between these indices and water metric is indirect, since none of them include spectral bands in the SWIR region where water absorption is strong. However, there is a strong link between grass water content, chlorophyll activity and LAI in this ecosystem. During wet periods the grass grows very rapidly, increasing the LAI, biomass and chlorophyll content, but as soon as the dry season starts with high temperatures and low rainfall the grass becomes cured rapidly losing all chlorophyll and quickly decreasing the LAI and biomass. This explains the empirical relationships with high $R^{2}$ between water metrics and indices sensible to chlorophyll activity, or those more sensible to water in the SWIR region. In addition, it is remarkable that MODIS estimations presented higher $R^{2}$ than proximal sensing. Bootstrap confidence intervals indicated that $R^{2}$ and RRMSE presented large intervals, larger when using MODIS images. Roberts et al. (2006) also observed different correlations between indices and platforms and the discrepancies here need further investigation. The difference in the confidence interval amplitude between proximal sensing and MODIS can be explained because the pixel included

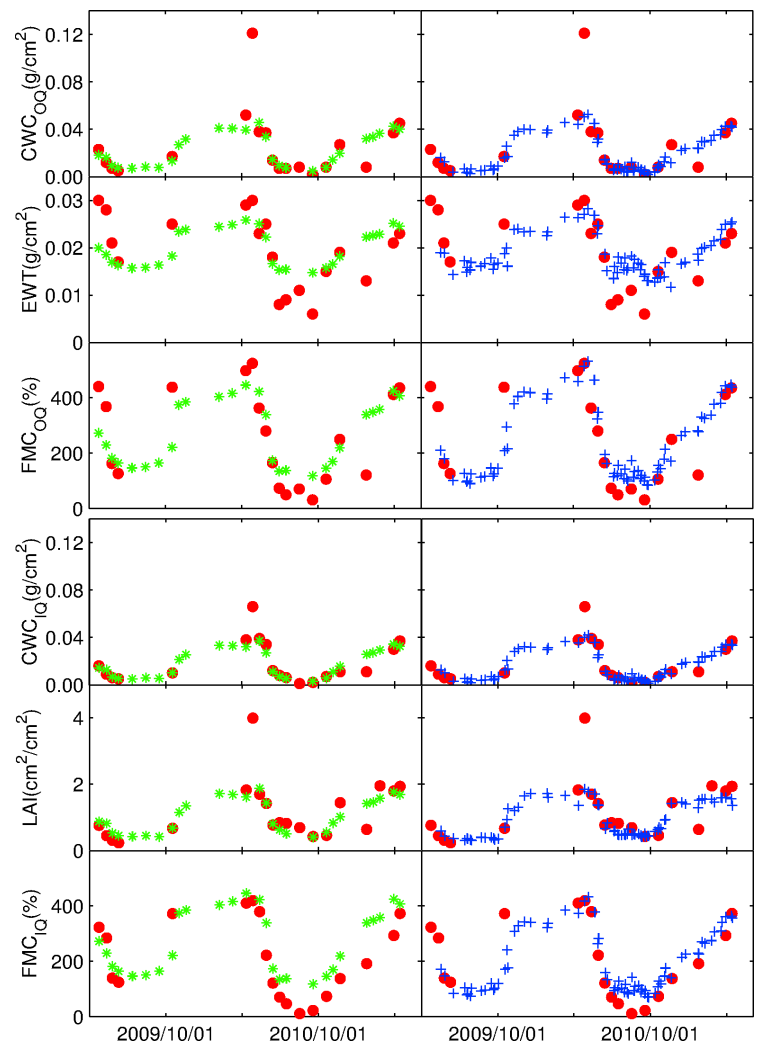

Figure 9. Temporal evolution of the observed (red circles) and estimated $\mathrm{FMC}_{\mathrm{OQ}}, \mathrm{FMC}_{\mathrm{IQ}}$, EWT, LAI, CWC $\mathrm{OQ}$ and $\mathrm{CWC}_{\mathrm{IQ}}$ obtained for proximal sensing (green asterisks) and MODIS (blue crosses). Fitting equations are presented in Table 2.

not only grass but also trees, their shades, and other marginal covers like bare soil and a water pond (Fig. 1), and its view angle could be up to $20^{\circ}$ whilst proximal sensing measures only two transects within each of the six plots and provides 
only nadiral measurements of herbaceous cover which could be more affected by the soil signal.

Similar to this study, Casas et al. (2014) reliably predicted water content variables in California (USA) from GEMI, NDII and EVI using simulated MODIS spectral response from airborne hyperspectral AVIRIS instrument. In their case, VARI was actually the most accurate for grasslands (FMC and CWC), chaparral (EWT, FMC and CWC) and a Mediterranean oak forest (EWT). On the contrary, VARI showed very poor accuracies in our case to estimate FMC, EWT and CWC, but was still capable of capturing the variability in LAI (Fig. 4). This fact also contradicts other studies that predicted FMC from VARI on chaparral (Peterson et al., 2008; Roberts et al., 2006; Stow et al., 2005, 2006). VARI was developed to detect vegetation fraction in homogenous wheat crops (Gitelson et al., 2002b), but neither Gitelson et al. (2002a) nor the above studies have tested this spectral index to detect vegetation water content on sites like ours, with strong seasonal changes in species composition and LAI.

The empirical methods calibrated for this specific site outperformed the physical RTM estimates for CWC and FMC (Figs. 7 and 8). This confirms the results in Casas et al. (2014) where the CWC algorithm based on RTM inversion developed by Trombetti et al. (2008) also failed to improve results from empirical estimates. Regarding the RTMbased FMC estimates, considering that the FMC inversion models were not calibrated with any data from the field campaign and that the results were similar to those obtained using empirical approach (Fig. 7) we believe that the models can be applied in other similar areas.

Future work in this line can still be done, testing other inversion techniques, using multiple observations or other optimization algorithms might help to improve the performance of physical-based estimates of biophysical variables of vegetation.

\section{Conclusions}

This work showed a complete analysis of three metrics, EWT, FMC and CWC, to measure grass water content at two different spatial scales by using proximal sensing from a field spectroradiometer and MODIS images. The temporal changes in these metrics are more critical than their spatial variation within the MODIS pixel. Results indicated that larger samples collected using quadrants as spatial reference sampling units are more representative than small samples in order to follow the temporal trends in FMC and CWC. Protocol standardization should be considered to make different data sets comparable both spatially and temporally. Due to the high seasonal Dm variability, a constant annual value should not be used to estimate EWT from FMC in this ecosystem. The dependence of CWC on LAI makes this vegetation water content variable easier to predict than FMC or
EWT in grasslands due to the strong existing link between LAI, water content and chlorophyll activity.

GEMI, NDII and EVI reliably predicted vegetation water content. The best empirical estimator differed between sensors. Empirical models based on vegetation indices showed higher $R^{2}$ for MODIS than from proximal sensing, probably due to differences induced by observation geometry and canopy observed. These empirical methods still exceed RTM inversions developed for other sites to predict FMC (Jurdao et al., 2013; Yebra et al., 2008b) and CWC (Trombetti et al., 2008). Conclusions from this study are much related to grassland physiology and cannot be extended to other vegetation types such as forest or shrubs.

Acknowledgements. This study has been carried out in the context of the BIOSPEC (CGL2008-02301) and FLUXPEC (CGL201234383) projects funded by the Spanish Ministry of Science and Innovation and the Ministry of Economy and Competitiveness respectively and the SENSORVEG (FP7-PEOPLE-2009-IRSES) action. The FPI grant program supported Gorka Mendiguren predoctoral research (BES-2009-026831) as well as short stays at the University of Copenhagen during year 2011 (EEBB-201144463) and 2012 (EEBB-I-12-04542) and to Rasmus Fensholt for hosting in the department. All the people involved in the field work campaigns from different institution: Spanish Council for Scientific Research, University of Alcalá de Henares, University of Zaragoza, CEAM and Instituto Nacional de Investigaciones Agrarias (INIA) are acknowledged. Collaboration with NASA Terrestrial Hydrology Program (grant \# NNX09AN51G) and David Riaño for his comments and suggestions are also acknowledged. The first author would like to thank Spanish INEM for its funding support.

Edited by: E. Tomelleri

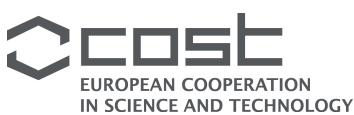

This publication was supported by COST - www.cost.eu

\section{References}

Bowyer, P. and Danson, F. M.: Sensitivity of spectral reflectance to variation in live fuel moisture content at leaf and canopy level, Remote Sens. Environ., 92, 297-308, 2004.

Camarero, J. J., Olano, J. M., Arroyo Alfaro, S. J., FernándezMarín, B., Becerril, J. M., and García-Plazaola, J. I.: Photoprotection mechanisms in Quercus ilex under contrasting climatic conditions, Flora: Morphology, Distribution, Funct. Ecol. Plants, 207, 557-564, 2012.

Casado, M. A., de Miguel, J. M., Sterling, A., Peco, B., Galiano, E. F., and Pineda, F. D.: Production and spatial structure of Mediterranean pastures in different stages of ecological succession, Vegetatio, 64, 75-86, doi:10.1007/BF00044783, 1986.

Casas, A., Riaño, D., Ustin, S. L., Dennison, P., and Salas, J.: Estimation of water-related biochemical and biophysical vegetation properties using multitemporal airborne hyperspectral data and its comparison to MODIS spectral response, Remote Sens. Environ., 148, 28-41, doi:10.1016/j.rse.2014.03.011, 2014. 
Castro, E. B.: Los Bosques Ibéricos: Una Interpretación Geobotánica, Editorial Planeta S. A. Barcelona, 1997.

Ceccato, P., Flasse, S., Tarantola, S., Jacquemoud, S., and Grégoire, J.-M.: Detecting vegetation leaf water content using reflectance in the optical domain, Remote Sens. Environ., 77, 22-33, 2001.

Ceccato, P., Gobron, N., Flasse, S., Pinty, B., and Tarantola, S.: Designing a spectral index to estimate vegetation water content from remote sensing data: Part 1: Theoretical approach, Remote Sens. Environ., 82, 188-197, 2002.

Chaves, M. M., Maroco, J. P., and Pereira, J. S.: Understanding plant responses to drought from genes to the whole plant, Funct. Plant Biol., 30, 239-264, doi:10.1071/FP02076, 2003.

Cheng, Y.-B., Ustin, S. L., Riaño, D., and Vanderbilt, V. C.: Water content estimation from hyperspectral images and MODIS indexes in Southeastern Arizona, Remote Sens. Environ., 112, 363-374, 2008.

Chuvieco, E., Aguado, I., Cocero, D., and Riaño, D.: Design of an empirical index to estimate fuel moisture content from NOAAAVHRR images in forest fire danger studies, Int. J. Remote Sens., 24, 1621-1637, 2003.

Chuvieco, E., Cocero, D., Riaño, D., Martin, P., Martínez-Vega, J., de la Riva, J., and Pérez, F.: Combining NDVI and surface temperature for the estimation of live fuel moisture content in forest fire danger rating, Remote Sens. Environ., 92, 322-331, 2004.

Chuvieco, E., Wagtendok, J., Riaño, D., Yebra, M., and Ustin, S.: Estimation of fuel conditions for fire danger assessment, in: Earth observation of wildland fires in Mediterranean ecosystems, Springer, Berlin Heidelberg, 83-96, 2009.

Danson, F., Steven, M. D., Malthus, T. J., and Clark, J. A.: Highspectral resolution data for determining leaf water content, Int. J. Remote Sens., 13, 461-470, 1992.

Datt, B.: Remote sensing of water content in Eucalyptus leaves, Aust. J. Bot., 47, 909-923, 1999.

Desbois, N., Deshayes, M., and Beudin, A.: A Review of Remote Sensing Methods for the Study of Large Wildland Fires, edited by: Chuvieco, E., Protocol for fuel moisture content measurements, 61-72, 1997.

Faurtyot, T. and Baret, F.: Vegetation water and dry matter contents estimated from top-of-the-atmosphere reflectance data: A simulation study, Remote Sens. Environ., 61, 34-45, doi:10.1016/S0034-4257(96)00238-6, 1997.

Gao, B.-C.: NDWI A normalized difference water index for remote sensing of vegetation liquid water from space, Remote Sens. Environ., 58, 257-266, 1996.

García, M., Chuvieco, E., Nieto, H., and Aguado, I.: Combining AVHRR and meteorological data for estimating live fuel moisture content, Remote Sens. Environ., 112, 3618-3627, 2008.

Gitelson, A. A., Kaufman, Y. J., Stark, R., and Rundquist, D.: Novel algorithms for remote estimation of vegetation fraction, Remote Sens. Environ., 80, 76-87, 2002a.

Gitelson, A. A., Stark, R., Grits, U., Rundquist, D., Kaufman, Y., and Derry, D.: Vegetation and soil lines in visible spectral space: A concept and technique for remote estimation of vegetation fraction, Int. J. Remote Sens., 23, 2537-2562, doi:10.1080/01431160110107806, $2002 b$.

Hardisky, M. A., Klemas, V., and Smart, R. M.: The influence of soil salinity, growth form, and leaf moisture on the spectral radiance of Spartina alterniflora canopies, Photogramm. Eng. Remote Sens., 49, 77-83, 1983.
He, Y., Guo, X., and Wilmshurst, J. F.: Comparison of different methods for measuring leaf area index in a mixed grassland, Can. J. Plant Sci., 87, 803-813, doi:10.4141/cjps07024, 2007.

Huemmrich, K. F.: The GeoSail model: a simple addition to the SAIL model to describe discontinuous canopy reflectance, Remote Sens. Environ., 75, 423-431, doi:10.1016/S00344257(00)00184-X, 2001.

Huete, A.: A soil-adjusted vegetation index (SAVI), Remote Sens. Environ., 25, 295-309, 1988.

Huete, A., Didan, K., Miura, T., Rodriguez, E. P., Gao, X., and Ferreira, L. G.: Overview of the radiometric and biophysical performance of the MODIS vegetation indices, Remote Sens. Environ., 83, 195-213, 2002.

Jacquemoud, S. and Baret, F.: PROSPECT: A model of leaf optical properties spectra, Remote Sens. Environ., 34, 75-91, doi:10.1016/0034-4257(90)90100-Z, 1990.

Jacquemoud, S., Baret, F., Andrieu, B., Danson, F. M., and Jaggard, K.: Extraction of vegetation biophysical parameters by inversion of the PROSPECT + SAIL models on sugar beet canopy reflectance data, Application to TM and AVIRIS sensors, Remote Sens. Environ., 52, 163-172, doi:10.1016/0034-4257(95)00018V, 1995.

Jurdao, S., Yebra, M., Guerschman, J. P., and Chuvieco, E.: Regional estimation of woodland moisture content by inverting Radiative Transfer Models, Remote Sens. Environ., 132, 59-70, doi:10.1016/j.rse.2013.01.004, 2013.

Law, B., Arkebauer, T., Campbell, J., Chen, J., Sun, O., Schwartz, M., van Ingen, C., and Verma, S.: Terrestrial carbon observations: protocols for vegetation sampling and data submission, Terrestrial Carbon Observations Panel of the Global Terrestrial Observing System, Rome, Italy, 2008.

Paltridge, G. W. and Barber, J.: Monitoring grassland dryness and fire potential in australia with NOAA/AVHRR data, Remote Sens. Environ., 25, 381-394, doi:10.1016/0034-4257(88)901101, 1988.

Peñuelas, J., Savé, R., Marfà , O., and Serrano, L.: Remotely measured canopy temperature of greenhouse strawberries as indicator of water status and yield under mild and very mild water stress conditions, Agr. Forest Meteorol., 58, 63-77, 1992.

Peterson, S. H., Roberts, D. A., and Dennison, P. E.: Mapping live fuel moisture with MODIS data: A multiple regression approach, Remote Sens. Environ., 112, 4272-4284, doi:10.1016/j.rse.2008.07.012, 2008 .

Pinty, B. and Verstraete, M. M.: GEMI: a non-linear index to monitor global vegetation from satellites, Plant Ecol., 101, 15-20, 1992.

Riaño, D., Vaughan, P., Chuvieco, E., Zarco-Tejada, P. J., and Ustin, S. L.: Estimation of fuel moisture content by inversion of radiative transfer models to simulate equivalent water thickness and dry matter content: analysis at leaf and canopy level, IEEE T. Geosci. Remote, 43, 819-826, doi:10.1109/tgrs.2005.843316, 2005.

Richter, K., Atzberger, C., Hank, T. B., and Mauser, W.: Derivation of biophysical variables from Earth observation data: validation and statistical measures, J. Appl. Remote Sens., 6, 063557, doi:10.1117/1.jrs.6.063557, 2012.

Roberts, D. A., Dennison, P. E., Peterson, S., Sweeney, S., and Rechel, J.: Evaluation of Airborne Visible/Infrared Imaging Spectrometer (AVIRIS) and Moderate Resolution Imaging Spec- 
trometer (MODIS) measures of live fuel moisture and fuel condition in a shrubland ecosystem in southern California, J. Geophys. Res.-Biogeo., 111, G04S02, doi:10.1029/2005jg000113, 2006.

Rouse, J. W., Haas, R. H., Deering, D. W., and Schell, J. A.: Monitoring the vernal advancement and retrogradation (green wave effect) of natural vegetation, Goddard Space Flight Center, Greenbelt, MD, 87 pp., 1973.

Sepulcre-Cantó, G., Zarco-Tejada, P. J., Jiménez-Muñoz, J. C., Sobrino, J. A., de Miguel, E., and Villalobos, F. J.: Detection of water stress in an olive orchard with thermal remote sensing imagery, Agr. Forest Meteorol., 136, 31-44, 2006.

Sims, D. A. and Gamon, J. A.: Estimation of vegetation water content and photosynthetic tissue area from spectral reflectance: a comparison of indices based on liquid water and chlorophyll absorption features, Remote Sens. Environ., 84, 526-537, doi:10.1016/S0034-4257(02)00151-7, 2003.

Steyerberg, E. W., Harrell Jr, F. E., Borsboom, G. J. J. M., Eijkemans, M. J. C., Vergouwe, Y., and Habbema, J. D. F.: Internal validation of predictive models: Efficiency of some procedures for logistic regression analysis, J. Clin. Epidemiol., 54, 774-781, doi:10.1016/S0895-4356(01)00341-9, 2001.

Stow, D., Niphadkar, M., and Kaiser, J.: MODIS-derived visible atmospherically resistant index for monitoring chaparral moisture content, Int. J. Remote Sens., 26, 3867-3873, doi:10.1080/01431160500185342, 2005.

Stow, D., Niphadkar, M., and Kaiser, J.: Time series of chaparral live fuel moisture maps derived from MODIS satellite data, Int. J. Wildland Fire, 15, 347-360, doi:10.1071/WF05060, 2006.

Taiz, L. and Zeiger, E.: Plant Physiology, Sinauer Associates, Incorporated, Sunderland, 2010.

Taylor, K. E.: Summarizing multiple aspects of model performance in a single diagram, J. Geophys. Res.-Atmos., 106, 7183-7192, 2001.
Trombetti, M., Riaño, D., Rubio, M. A., Cheng, Y. B., and Ustin, S. L.: Multi-temporal vegetation canopy water content retrieval and interpretation using artificial neural networks for the continental USA, Remote Sens. Environ., 112, 203-215, 2008.

Verbesselt, J., Somers, B., Lhermitte, S., Jonckheere, I., van Aardt, J., and Coppin, P.: Monitoring herbaceous fuel moisture content with SPOT VEGETATION time-series for fire risk prediction in savanna ecosystems, Remote Sens. Environ., 108, 357-368, 2007.

Wolfe, R. E., Nishihama, M., Fleig, A. J., Kuyper, J. A., Roy, D. P., Storey, J. C., and Patt, F. S.: Achieving sub-pixel geolocation accuracy in support of MODIS land science, Remote Sens. Environ., 83, 31-49, doi:10.1016/S0034-4257(02)00085-8, 2002.

Yebra, M., Chuvieco, E., and Aguado, I.: Comparación entre modelos empíricos y de transferencia radiativa para estimar contenido de humedad en pastizales: Poder de generalización, Revista de Teledetección, 29, 73-90, 2008a.

Yebra, M., Chuvieco, E., and Riaño, D.: Estimation of live fuel moisture content from MODIS images for fire risk assessment, Agr. Forest Meteorol., 148, 523-536, 2008 b.

Yebra, M., Dennison, P. E., Chuvieco, E., Riaño, D., Zylstra, P., Hunt Jr, E. R., Danson, F. M., Qi, Y., and Jurdao, S.: A global review of remote sensing of live fuel moisture content for fire danger assessment: Moving towards operational products, Remote Sens. Environ., 136, 455-468, doi:10.1016/j.rse.2013.05.029, 2013.

Zarco-Tejada, P. J., Rueda, C. A., and Ustin, S. L.: Water content estimation in vegetation with MODIS reflectance data and model inversion methods, Remote Sens. Environ., 85, 109-124, 2003. 